\title{
10p13-p14 Deletion Syndrome
}

National Cancer Institute

\section{Source}

National Cancer Institute. 10p13-p14 Deletion Syndrome. NCI Thesaurus. Code C130982.

A congenital condition caused by a deletion on the short arm of chromosome 10p13-

p14. The NEBL gene, encoding nebulette, a heart-specific component of the sarcomere,

may be responsible for the clinical findings. The condition is characterized by

immunodeficiency, unusual facies, congenital heart anomalies (tetralogy of Fallot,

pulmonary atresia with ventricular septal defect, truncus arteriosus, interrupted aortic

arch, isolated anomalies of the aortic arch, and ventricular septal defect),

hypoparathyroidism, and increased susceptibility to infections. 